\title{
Pengaruh Rasa Percaya Diri Terhadap Motivasi Berprestasi Siswa pada Mata Pelajaran IPA
}

\author{
Asiyah, Ahmad Walid, Raden Gamal Tamrin Kusumah \\ asiyah@iainbengkulu.ac.id, ahmadwalid@iainbengkulu.ac.id, raden@iainbengkulu.ac.id \\ Program Doktoral, Program Doktoral, Science Education \\ Institut Agama Islam Negeri Bengkulu
}

The Effect Of Self Confidence Towards Students'Motivation For Achievements In Science Lesson

\begin{abstract}
This research aims to examine whether there is an influence of self-confidence in students' motivation to achievement in science lesson in elementary schools. This is a field research, where the researchers are involved directly down to the place of research to collect the data relevant to the indicators in the research objectives, which classifies this as a field research with a correlational quantitative approach. Correlational quantitative research is research to determine the level of relations between two or more variables, without making changes, additions, or manipulations of data that already exists. The data analysis techniques was done by observations and questionnaires instruments. Based on the results of analysis with manual calculations, the $R$ Square correlation coefficient is 0.39 or $39 \%$ which means that selfconfidence affects student motivation for achievement, while the rest is influenced by other variables of $61 \%$ that were not examined. This indicates that the variations of confidence with motivation of achievement is $39 \%$. Based on the calculation, the tcount valued $2.898>$ from $t_{\text {table, }}$ with $d k=48$, worth 2.011 which means there is an influence of confidence $(X)$ to motivation for achievement $(Y)$. The hypothesis for Ha is accepted and Ho is rejected.
\end{abstract}

Keywords: Self Confidence, Motivation, Student Achievements, Science Lesson

Article Info

Received date: 21 Maret 2019 Revised date: 25 Agustus $2019 \quad$ Accepted date: 19 September 2019

\section{PENDAHULUAN}

Pendidikan merupakan sebuah sarana yang memfasilitasi anak untuk belajar dan mengembangkan potensi. Pendidikan dalam arti sempit diartikan sebagai sekolah. Sekolah dalam Kamus Besar Bahasa Indonesia, diartikan sebagai suatu lembaga untuk belajar dan mengajar serta tempat menerima dan memberi pelajaran. Pendidikan adalah pengajaran yang diselenggarakan di sekolah sebagai lembaga pendidikan formal. Selain itu pendidikan dapat juga diartikan sebagai segala pengaruh yang sdiupayakan sekolah terhadap anak dan remaja yang diserahkan kepadanya agar mempunyai kemampuan yang sempurna dan kesadaran penuh terhadap hubungan-hubungan dan tugastugas sosial mereka.

Dalam Undang-Undang Sistem Pendidikan Nasional No : 20 Tahun 2003 Pasal 1, dijelaskan bahwa : Pendidikan adalah usaha sadar dan terencana untuk mewujudkan suasana belajar dan proses pembelajaran agar peserta didik secara aktif dapat mengembangkan potensi dirinya untuk memilki kekuatan spiritual keagamaan, pengendalian diri, kepribadian, kecerdasan serta keterampilan yang diperlukan dirinya, masyarakat, bangsa dan Negara. Tujuan Pendidikan Nasional diidealisasikan sebagaimana termuat dalam UU RI No. 2 Tahun 1989 Pasal 4, dimana "Pendidikan Nasional bertujuan mencerdaskan kehidupan bangsa dan mengembangkan manusia Indonesia seutuhnya, yaitu manusia beriman dan bertaqwa terhadap Tuhan Yang Maha Esa, berbudi pekerti luhur, memiliki pengetahuan dan keterampilan, kepribadian yang mantap dan mandiri, serta tanggung jawab kemasyarakatan dan kebangsaan." Jika idealisasi itu menjelma dalam realita, maka arus siswa akan memasuki pendidikan kejenjang yang lebih tinggi, mereka akan menjadi modal utama lahirnya SDM yang terampil dan memiliki moralitas tinggi (Ismiyati, 2015). 
Kepribadian yang dimaksudkan dalam tujuan pendidikan nasional Undang Undang RI no. 2 tahun 1989 pasal 4 adalah ciri atau karakteristik atau gaya atau sifat khas seseorang yang bersumber dari bentukan yang diterima lingkungan. Kepribadian meliputi tingkah laku, cara berpikir, perasaan, gerak hati, usaha, aksi, tanggapan terhadap kesempatan, tekanan dan cara sehari-hari dalam berinteraksi dengan orang lain.

Salah satu bagian dari kepribadian diri adalah rasa percaya diri yang menjadi faktor internal dalam diri pribadi. Kepercayaan diri siswa berdasarkan observasi awal di SD Negeri 18 Seluma ditemukan masih rendahnya sikap percaya diri siswa. Hal ini terlihat pada saat pembelajaran IPA berlangsung. Masih banyak siswa yang tidak mampu bertanya dan berpendapat diwaktu diberikan kesempatan bertanya ataupun berpendapat. Selain itu juga siswa juga masih banyak terlihat melirik dan bertanya ke teman sebangku saat diberikan tugas pretest mengenai mata pelajaran IPA. Dari pengamatan itu disimpulkan bahwa siswa SD Negeri 18 Seluma belum tertanam sikap rasa percaya diri dalam siswa. Hal ini sejalan dengan yang ditulis oleh Novena \& Kriswandani (2018) yang menyebutkan bahwa pada studi pendahuluan rasa percaya diri yang dimiliki belum tinggi. Indikator motivasi menurut Desi Putrianasari \& Wasitohadi, (2015); Ismiyati, (2015); Mawardi, Kristin, Anugraheni, \& Rahayu, (2019) bisa dirasakan dan dilihat dari energi yang dikeluarkan oleh siswa pada saat pembelajaran berlangsung. Energi yang dikeluarkan tersebut termanifestasikan dalam bentuk keaktifan siswa dalam belajar. Pada observasi ini belum terlihat adanya gerakan tersebut pada siswa.

Salah satu faktor yang perlu dikembangkan apabila siswa berprestasi adalah rasa percaya diri karena adanya rasa percaya diri yang tinggi akan semakin membuat seseorang tersebut berhasil dalam menjalani suatu proses interaksi tersebut, meskipun masih banyak lagi faktor-faktor lain yang mendukung (Gael, 1994; Surya, 2007). Menurut Albert Bandura, psikolog dan peneliti dari Stanford University, kepercayaan diri adalah "rasa percaya terhadap kemampuan diri dalam menyatakan dan menggerakkan motivasi dan semua sumber daya yang dibutuhkan dan memunculkannya dalam tindakan yang sesuai dengan apa yang harus diselesaikan, atau sesuai tuntutan tugas" (Bekleyen, 2011; Jamil, 2019; Nashar, 2004; Sardiman, 2004). Memiliki rasa percaya diri yang tinggi juga merupakan hal yang sangat bermanfaat bagi perkembangan kepribadian individu. Adanya rasa percaya diri yang tinggi akan membuat individu mersa optimis, dan dari rasa optimis ini akan mempunyai pengaruh yang besar bagi perkembangan kepribadian dan kehidupan yang dijalaninya

Pada kenyataan, tidak semua individu memilki rasa percaya diri yang tinggi, dan kurangnya rasa percaya diri yang tinggi juga merupakan gejala khas yang banyak menimpa setiap orang, apalagi dalam masa bersekolah (Gael, 1994; Kusumah \& Munandar, 2017; Surya, 2007). Jadi dapat dikatakan bahwa orang yang mempunyai konsep diri yang positif terhadap dirinya maka dia memelihara kemampuannya dengan perasaan yang positif terhadap dirinya, terhadap keraguan akan kemampuannya (Kusumah \& Munandar, 2017; Walid, Putra, \& Asiyah, 2019). Sebaliknya jika orang yang kepercayaan dirinya rendah, maka pada dirinya terdapat keraguan, kehampaan dan keputusan individu dalam menghadapi tuntutan dan tantangan hidupnya, serta menghasilkan penilaian yang rendah atas dirinya dalam kaitannya dengan orang lain. Tujuan penelitian ini adalah untuk menguji apakah terdapat pengaruh rasa percaya diri terhadap motivasi berprestasi siswa pada mata pelajaran IPA di Sekolah Dasar

\section{KAJIAN PUSTAKA}

\section{Percaya Diri}

Percaya diri dalam setiap kegiatan yang akan kita lakukan sepanjang hari merupakan sebuah kewajiban. Jika setiap orang tidak memiliki kepercayaan diri dalam mengerjakan sesuatu, tentu saja hasil yang akan diharapkan menjadi tidak sesuai dengan yang direncanakan. Kepercayaan diri merupakan sikap pada diri seseorang yang bisa menerima kenyataan, mengembangkan kesadaran diri, berfikir positif, memiliki kemandirian dan mempunyai kemampuan untuk memiliki segala sesuatu yang di inginkan (W. Liu, Zhang, Chen, \& Yu, 2018; Sharour, 2019). Kepercayaan diri juga merupakan bagian dari self-efficacy menurut teori yang disampaikan oleh Bandura, (1997) karena ada komponen dari gesture ataupun sikap-sikap yang memiliki kesamaan sifat. Selain itu juga penelitian yang dilakukan oleh Novena \& Kriswandani, (2018) menunjukkan bahwa sikap-sikap yang dimiliki siswa dalam pembelajaran berupa keaktifan, keyakinan diri dalam menjawab pertanyaan lisan dari guru, juga sikap dalam mendorong diri sendiri hingga pada batasnya untuk selalu aktif dalam pembelajaran. 
Sedangkan menurut Hambly dalam Ameliah \& Munawaroh (2016) kepercayaan diri bermakna bahwa keyakinan terhadap diri sendiri sehingga mampu menangani segala situasi dengan tenang, kepercayaan diri lebih banyak berkaitan dengan hubungan seseorang dengan orang lain. Tidak merasa inferior di hadapan siapapun dan tidak merasa canggung apabila berhadapan dengan banyak orang. Kepercayaan diri juga memicu diri sendiri untuk bertindak dengan rasa penuh tanggung jawab karena yakin telah memiliki pengetahuan yang cukup melakukan tindakan yang sesuai dengan prosedur (W. Liu et al., 2018; X. Liu, Xu, Montes, \& Herrera, 2019; Sharour, 2019). Prosedur yang dimaksud adalah hasil manifestasi atau sintesis dari pemeroleh pengetahuan dari proses belajar ((Kusumah \& Munandar, 2017; Novena \& Kriswandani, 2018)

Berdasarkan pengertian dari ahli tersebut dapat disimpulkan bahwa percaya diri memiliki arti meyakinkan pada kemampuan dan penilaian (judgement) diri sendiri dalam melakukan tugas dan memilih pendekatan yang dirasa cukup efektif. Persamaan dari sintesis teori mengenai pengertian kepercayaan diri dari beberapa penelitian diatas yaitu adalah sama-sama memiliki kepercayaan terhadap diri sendiri dalam menghadapi fenomena yang terjadi di depan matanya. Sedangkan perbedaannya adalah, ada yang menyatakan harus ada pengetahuan awal terlebih dahulu supaya terbentuk kepercayaan diri (Bandura, 1997; Kusumah \& Munandar, 2017; Novena \& Kriswandani, 2018). Kemudian menurut pendapat lain ada yang hanya cukup keyakinan ataupun kepercayaan diri saja tanpa menyebutkan modal pengetahuan (Hambly, 1992; W. Liu et al., 2018; X. Liu et al., 2019; Sharour, 2019)

Percaya diri bisa disebut sikap yang positif, dimana seseorang mampu untuk mengembangkan nilai positif terhadap diri sendiri maupun terhadap lingkungan yang telah dihadapinya. Hal ini bukan berarti seorang individu itu bisa melakukan segala seorang diri. Kepercayaan diri yang terlalu tinggi akan menyebabkan adanya degradasi mental yang sesungguhnya atau yang ada dalam dirinya tanpa melihat baik dan buruk sifat tersebut.

\section{Prestasi Belajar}

Banyak para ahli yang telah mendefinisikan prestasi belajar. Hal ini dilakukan karena menyesuaikan dengan kontekstual yang ada sesuai dengan zaman yang dihadapinya. Menurut Wijaya (1992), prestasi belajar bisa dalam bentuk pernyataan berupa angka ataupun nilai tingkah laku. Menurut Nawawi (1998, p.100) prestasi belajar adalah tingkatan keberhasilan siswa dalam mempelajari materi pelajaran di sekolah yang dinyatakan dalam bentuk skor yang diperoleh dari hasil tes, mengenai sejumlah materi tertentu. Sedangkan menurut Tu'u (2004) memberikan banyak pengertian prestasi belajar siswa sebagai berikut: a). Prestasi belajar siswa adalah hasil belajar yang dicapai siswa ketika mengikuti dan mengerjakan tugas dan kegiatan pembelajaran di sekolah. b). Prestasi belajar siswa tersebut terutama dinilai aspek kognitifnya karena bersangkutan dengan kemampuan siswa dalam pengetahuan atau ingatan, pemahaman, aplikasi, analisis, sintesa dan evaluasi. c). Prestasi belajar siswa dibuktikan dan ditunjukan melalui nilai atau angka nilai dari hasil evaluasi yang dilakukan oleh guru terhadap tugas siswa dan ulangan-ulangan atau ujian yang ditempuhnya. Prestasi belajar juga merupakan manifestasi dari serangkaian pembelajaran yang telah dilakukan oleh siswa dan lingkungannya dengan berbagai macam faktor eksternal dan internal yang mempengaruhinya (Franke \& Bogner, 2013; Nath, 2012; Shen, McCaughtry, Martin, \& Fahlman, 2009). Manifestasi yang didapatkan merupakan hasil yang berupa hasil yang positif dengan kriteria tertentu yang telah ditetapkan oleh lembaga yang berwenang. Lembaga berwenang yang dimaksudkan adalah bisa berupa sekolah, lembaga pemerintah, kesepakatan orang tua siswa dengan sekolah dan lain sebagainya.

Dari berbagai pendapat dan teori yang telah dijelaskan sebelumnya, dapat disimpulkan bahwa prestasi belajar adalah hasil yang telah dicapai siswa dalam proses pembelajaran. Persamaan yang dapat diambil dari berbagai pendapat tersebut adalah adanya kesamaan kriteria mengenai pencapaian hasil belajar. Kriteria tertentu dari hasil belajar tersebut dinamakan dengan prestasi belajar. Tidak ada perbedaan sama sekali dalam beberapa teori yang telah dikemukakan, hanya menambahkan penjelasanpenjelasan yang memperdalam maksud dari teori tersebut.

Secara teoritis prestasi belajar memiliki kaitan erat dengan rasa percaya diri. Hal ini diungkapkan oleh Djamarah (2008) bahwa rasa percaya diri merupakan bagian dari faktor psikologis yang mempengaruhi prestasi belajar. Adapun faktor-faktor yang mempengaruhi proses dan prestasi belajar adalah ; a). Faktor Lingkungan b). Faktor Instrumental c). Faktor Fisiologis d). Faktor Psikologis. Hal ini sejalan dengan Astin dengan teori I-E-O (Inputs, Environment, Outcomes) Model (Ismiyati, 2015; Strayhorn, 2008). 


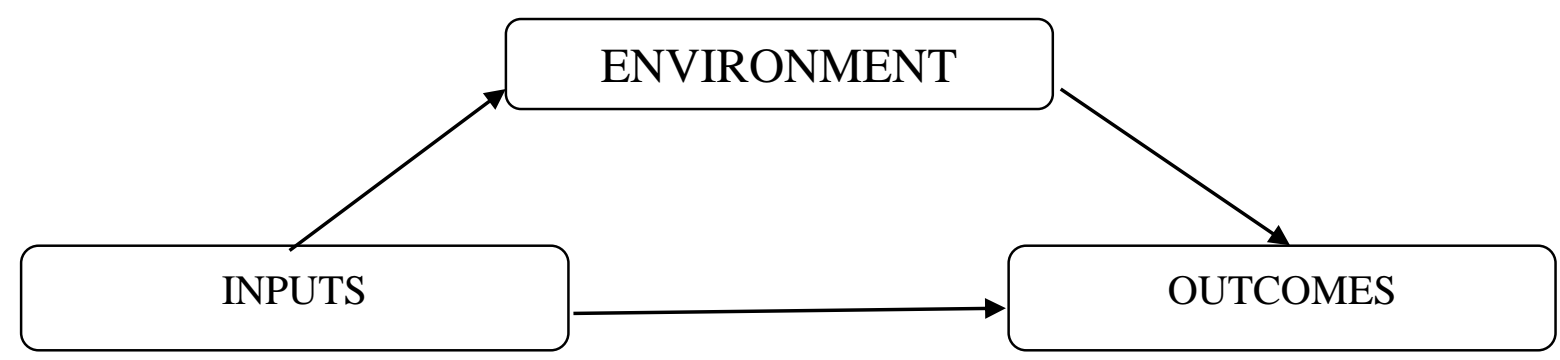

Gambar 1. Astin's I-E-O (Inputs, Environment, Outcomes) Model

\section{METODE PENELITIAN}

Penelitian ini adalah penelitian korelasional. Penelitian korelasional adalah penelitian yang dilakukan oleh peneliti untuk mengetahui tingkat hubungan antara dua variabel atau lebih, tanpa melakukan perubahan, tambahan, atau manipulasi terhadap data yang memang sudah ada (Arikunto, 2010). Penelitian kuantitatif bertujuan untuk mengkaji satu permasalahan dari suatu fenomena, menguji teori, serta mencari generalisasi yang mempunyai nilai prediktif.

Penelitian ini bertujuan untuk mengetahui korelasi antara kepercayaan diri dengan motivasi prestasi belajar yang dimiliki oleh siswa sekolah dasar. Tempat penelitian ini dilakukan di Sekolah Dasar Negeri 18 Seluma. Waktu penelitian selama kurang lebih 2 bulan.

Populasi dalam penelitian ini adalah Siswa SD Negeri 18 Seluma, yang berjumlah 230 orang siswa. Sedangkan sampel yang diambil dalam penelitian ini adalah sebanyak $25 \%$ dari jumlah populasi yang tersedia. Teknik pengambilan sampel yang digunakan adalah teknik sample random sampling.

Tabel 1. Populasi Penelitian

\begin{tabular}{ccccc}
\hline \multirow{2}{*}{ No } & \multirow{2}{*}{ Kelas } & \multicolumn{2}{c}{ Jenis Kelamin } & \multirow{2}{*}{ Jumlah } \\
\cline { 3 - 4 } $\mathbf{1}$ & I & $\mathbf{P}$ & $\mathbf{L}$ & \\
\hline $\mathbf{2}$ & II & 24 & 24 & 48 \\
\hline $\mathbf{3}$ & III & 14 & 29 & 49 \\
\hline $\mathbf{4}$ & IV & 17 & 13 & 27 \\
\hline $\mathbf{5}$ & V & 20 & 14 & 30 \\
\hline $\mathbf{6}$ & VI & 18 & 24 & 34 \\
\hline & Jumlah & $\mathbf{1 1 3}$ & $\mathbf{1 1 7}$ & $\mathbf{2 3 0}$ \\
\hline
\end{tabular}

Teknik simple random sampling merupakan teknik pengambilan sampel yang memberikan kesempatan yang sama kepada setiap anggota yang ada dalam suatu populasi untuk dijadikan sampel, dalam penelitian populasi penelitian adalah siswa SD Negeri 18 Seluma dan sampel penelitan berjumlah 59 orang. Dari 59 orang siswa sebagai responden tersebut, 9 orang siswa tidak ikut berpartisipasi, sehingga sampelnya menjadi 50 orang siswa.

Tabel 2. Sampel Penelitian

\begin{tabular}{ccccc}
\hline No & Kelas & Jumlah Siswa & Persentase & Sampel \\
\hline $\mathbf{1}$ & I & 48 & $25 \%$ & 12 \\
\hline $\mathbf{2}$ & II & 49 & $25 \%$ & 12 \\
\hline $\mathbf{3}$ & III & 27 & $25 \%$ & 7 \\
\hline $\mathbf{4}$ & IV & 30 & $25 \%$ & 8 \\
\hline $\mathbf{5}$ & V & 34 & $25 \%$ & 9 \\
\hline $\mathbf{6}$ & VI & 42 & $25 \%$ & 11 \\
\hline & Jumlah & $\mathbf{2 3 0}$ & & $\mathbf{5 9}$
\end{tabular}

Untuk memperoleh data yang diperlukan dalam penelitian ini digunakan instrumen observasi dan kuesioner. Observasi atau pengamatan digunakan dalam rangka mengumpul-kan data dalam suatu penelitian. Teknik pengumpulan data dengan observasi digunakan bila, penelitian berkenaan dengan 
perilaku manusia, proses kerja, gejala-gejala alam dan bila responden yang diamati tidak terlalu besar. Observasi atau pengamatan dilakukan untuk mendapat data keadaan Desa, warga yang berkenaan dengan penelitian dengan jalan mengamati dan mencatat.

Kuesioner atau angket adalah sejumlah pertanyaan tertulis yang digunakan untuk memperoleh informasi dari responden dalam arti laporan tentang pribadinya, atau hal-hal yang ia ketahui (Ansarin \& Khatibi, 2018; Azman, Muhammad, Nurkhamimi, \& Hasanah, 2018; Tagg \& Wang, 2016; Wijekoon et al., 2017; Yusrizal, Suliyanah, \& Basri, 2017). Angket yang digunakan adalah angket tertutup, maksudnya angket yang sudah tersedia jawabannya dan responden memilih diantara jawaban yang tersedia. Alasan pemilihan angket dalam penelitian ini dari segi teknis pelaksanaan angket adalah metode yang paling efektif, efesien, dan hemat waktu tenaga, dan biaya dalam proses penelitian.

Rasa percaya diri diukur dengan menilai setiap item dalam skala Likert, dimana setiap pernyataan memiliki empat alternative jawaban yaitu; Sangat Setuju (SS), Setuju (S), Tidak Setuju (TS), dan Sangat Tidak Setuju (STS). Skor yang diberikan bergerak dari skor 4 sampai dengan 1 dengan pemberian skor 4 untuk jawaban Sangat Setuju (SS), skor 3 untuk jawaban Setuju (S), 2 Skor untuk jawaban Tidak Setuju (TS) dan skor 1 untuk jawaban Sangat Tidak Setuju (STS).

Pada penelitian ini menggunakan variabel Rasa pecaya diri (X), dan motivasi berprestasi (Y) adapun kisi - kisi instrument adalah terlihat pada tabel 3 .

Tabel 3. Kisi - Kisi Instrumen

\begin{tabular}{|c|c|c|c|c|}
\hline No & Variabel & Indiktor & Nomor Item & $\mathbf{J m l}$ \\
\hline \multirow{2}{*}{1} & Rasa & - Percaya diri lahir & $1,3,5,7,2,4,6,8$ & 8 \\
\hline & Percaya Diri & - Percaya diri batin & $9,11,13,15,10,12,14,16$ & 9 \\
\hline \multirow[t]{5}{*}{2} & Motivasi & - Menyukai tugas & $1,2,3$ & 3 \\
\hline & Berprestasi & - Memiliki tujuan & $4,5,7$ & 3 \\
\hline & & - Bersedia menerima perubahan & 8,9 & 2 \\
\hline & & - Senang Bekerja Mandiri & 10,11 & 2 \\
\hline & & - Dorongan /Keinginan & 6,12 & 2 \\
\hline
\end{tabular}

\section{HASIL PENELITIAN DAN PEMBAHASAN}

\section{Hasil Penelitian}

Untuk mengetahui data pengaruh rasa percaya diri terhadap motivasi prestasi siswa pada mata pelajaran IPA SD Negeri 18 Seluma, dapat diperoleh dari hasil angket yang disebarkan kepada terhadap siswa. Adapun langkah-langkah untuk membuat distribusi tersebut adalah sebagai berikut.

Berdasarkan data penelitan yang telah dikumpulkan dari masing - masing variabel, yaitu variabel rasa percaya diri sebagai data variabel $\mathrm{X}$ dan perilaku kekerasan sebagai variabel $\mathrm{Y}$, kemudian data yang terkumpul dibuat tabel distribusi frekuensi seperti yang tercantum di tabel 4 dan 5 , serta pada gambar 1 dan 2. Penyajian data statistika ini berdasarkan pada cara penyajian data menurut Riduan dqn Sudijono (Riduwan, 2015; Sudijono, 2010)

Tabel 4. Data Frekuensi Rasa Percaya Diri

\begin{tabular}{|l|l|}
\hline Valid & 50 \\
Missing & 0 \\
Mean & 53.58 \\
Median & 54.00 \\
Mode & 55 \\
Std. Deviation & 4.845 \\
Variance & 23.473 \\
Minimum & 44 \\
Maximum & 66 \\
Sum & 2679 \\
\hline
\end{tabular}




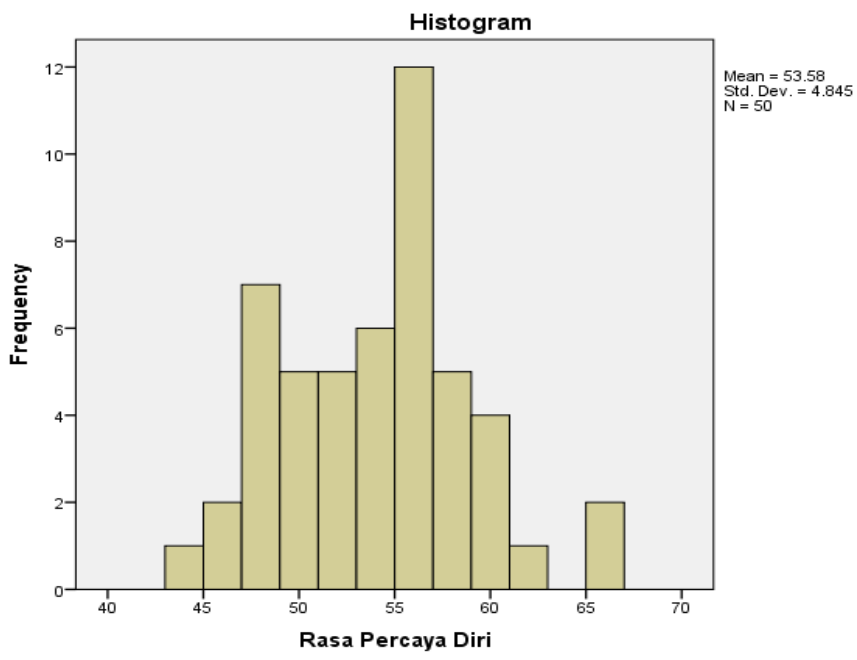

Gambar 2. Grafik Rasa Percaya Diri

Tabel 5. Data Frekuensi Motivasi Berprestasi

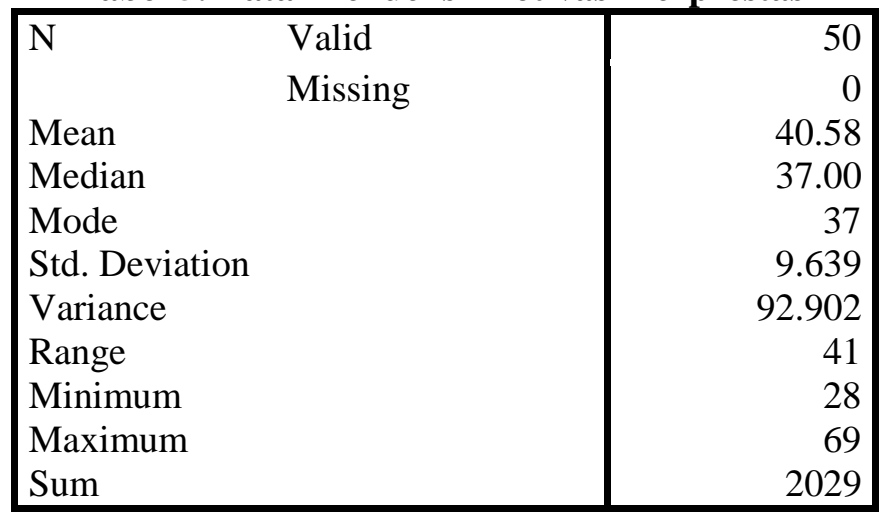

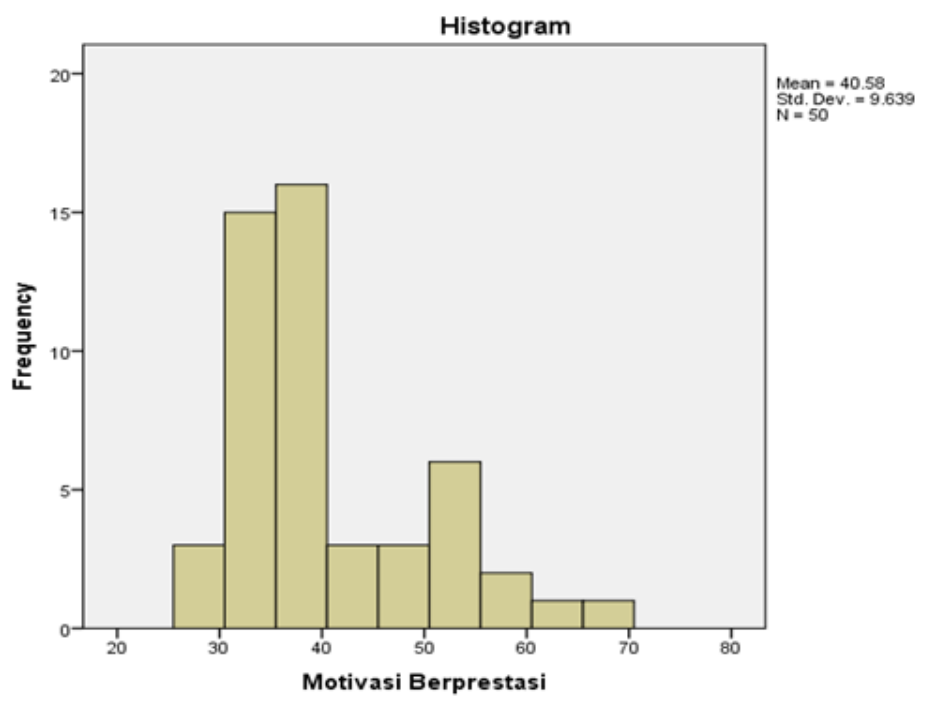

Gambar 3. Grafik Motivasi Berprestasi

Komputasi statistik yang dilakukan menemukan bahwa nilai koefisien korelasi antara percaya diri dan motivasi berprestasi siswa sebesar 0,624. Nilai $\mathrm{R}$ Square $=0,39$ atau $39 \%$, artinya bahwa rasa percaya diri berkontribusi terhadap motivasi berprestasi siswa seebesar $39 \%$, sedangkan sisanya $61 \%$ berasal dari variabel lain. 


\section{Pembahasan}

Tujuan penelitian ini bertujuan untuk mencari apakah terdapat pengaruh rasa percaya diri terhadap motivasi berprestasi siswa pada mata pelajaran IPA di SD Negeri 18 Seluma. Hal ini dilakukan karena berdasarkan fenomena yang terjadi dilapangan menunjukkan bahwa terdapat kegelisahan yang mendalam dari para siswa dalam pembelajaran IPA di sekolah.

Kepercayaan diri adalah suatu keyakinan seseorang terhadap segala aspek kelebihan yang dimilikinya dan keyakinan tersebut membuatnya merasa mampu untuk bisa mencapai berbagai tujuan di dalam hidupnya. Kepercayaan diri juga membuat seseorang melakukan hal yang positif sebagai aktualisasi dirinya dihadapan masyarakat (Anthony, 1992; Bandura, 1997; Hambly, 1992). Konkritnya di sekolah, siswa akan selalu aktif dalam pembelajaran, kemudian dalam mengerjakan tugas yang diberikannya, selalu dapat mengerjakannya dengan baik (Kusumah \& Munandar, 2017).

Motivasi berprestasi dalam penelitian ini diukur dengan pendapat responden tentang menyukai tugas yang menuntut tanggung jawab pribadi, memiliki tujuan yang realistis dan menantang, bersedia menerima perubahan dan umpan balik, senang bekerja mandiri, senang bersaing untuk mengungguli orang lain, dan keinginan/dorongan berprestasi. Hal ini sejalan dengan penelitian yang telah dilakukan oleh Hutauruk, Maulina, \& Manik, (2018); Jamil, (2019); Juita, (2019); Suarni, (2019); Walid et al., (2019). Selain itu, faktor kecil lain yang ikut dalam mempengaruhi hasil belajar adalah metode pembelajaran yang dilakukan oleh guru (Sari \& Yunianta, 2017).

Berdasarkan hasil analisis dengan perhitungan statistik diperoleh harga koefisien korelasi $\mathrm{R}$ Square $=0,39$ atau $39 \%$ yang memiliki arti bahwa rasa percaya diri mempengaruhi motivasi berprestasi siswa sedangkan sisanya dipengaruh oleh variabel-variabel lain sebesar $61 \%$ yang tidak diteliti, hal ini menunjukkan bahwa variasi rasa percaya diri dengan motivasi berprestasi sebesar 39\%. Berdasarkan hasil analisis penghitungan nilai thitung didapatkan nilai sebesar 2,898 > dari $t_{\text {tabel }}$ dengan $\mathrm{dk}=48$ bernilai 2,011 yang berarti ada pengaruh variabel rasa percaya diri $(\mathrm{X})$ dengan motivasi berprestasi $(\mathrm{Y})$ maka hipotesis untuk Ha diterima dan Ho ditolak.

Penelitian yang telah dilakukan menunjukkan bahwa terdapat pengaruh yang positif antara rasa percaya diri dengan motivasi berprestasi siswa dalam pembelajaran IPA di sekolah dasar. Korelasi yang positif yang terjadi tersebut diakibatkan oleh adanya interaksi yang sangat erat didalamnya. Kepercayaan diri yang dimiliki siswa dalam mengerjakan tugas maupun dalam mengikuti pembelajaran merupakan modal yang sangat utama dalam pembentukan motivasi berprestasi belajar (Franke \& Bogner, 2013; Nath, 2012; Shen et al., 2009).

Rasa percaya diri yang terbentuk pada diri siswa membuat siswa yakin dengan kemampuan yang dimilikinya sehingga menjadikan hal tersebut modal untuk motivasi untuk berprestasi siswa (Hambly, 1992; Tu'u, 2004). Rasa percaya diri yang terbentuk tersebut merupakan manifestasi dari berbagai tahapan pembelajaran berupa pengalaman belajar yang telah dilaluinya. Pengalaman yang didapatkan tersebut membuat siswa menjadi lebih percaya diri dalam mengerjakan tugas maupun menghadapi proses pembelajaran di kelas (Effendi, Mursilah, \& Mujiono, 2018; Ibrahim \& Suardiman, 2014). Sehingga menjadi modal pemicu berprestasi siswa di sekolah. Apalagi pada masa sekolah, siswa merupakan masa untuk mengaktualisasikan dirinya di hadapan masyarakat sekolah maupun masyarakat di lingkungan rumahnya. Sehingga itu menjadi modal motivasi untuk berprestasi diri.

\section{SIMPULAN DAN SARAN}

\section{Simpulan}

Berdasarkan Penelitian yang telah dilakukan, maka dapat diambil beberapa kesimpulan antara lain, terdapat hubungan positif yang signifikan antara rasa percaya diri dengan motivasi berprestasi. Semakin tinggi tingkat rasa percaya diri yang dialami, maka semakin tinggi pula motivasi berprestasi siswa. Sebaliknya, semakin rendah tingkat rasa percaya diri yang dialami, maka semakin rendah pula motivasi berprestasi siswa.

Koefisien determinasi (R Squared) variabel rasa percaya diri dengan variabel kecenderungan perilaku kekerasan terhadap anak adalah sebesar 0,340. Hasil tersebut menunjukkan bahwa sumbangan efektif rasa percaya diri terhadap motivasi berprestasi siswa adalah sebesar 39\%, sedangkan $61 \%$ lainnya dipengaruhi oleh variabel lain. 
Pengaruh Rasa Percaya Diri Terhadap Motivasi Berprestasi Siswa pada Mata Pelajaran IPA

(Asiyah, Ahmad Walid, Raden Gamal Tamrin Kusumah)

\section{Saran}

Dari hasil penelitian yang dilakukan di SD Negeri 18 Seluma, maka dapat disarankan dan diberi masukan kepada berbagai pihak yang bersangkutan, yaitu bahwa guru diharapkan tetap memberikan motivasi lebih sering agar dapat membantu siswa-siswa untuk menggunakan dan mengembangkan bakat-bakat serta menghargainya. Siswa sebagai generasi penerus, seyogyanya memiliki kemampuan untuk terus belajar menjadi diri sendiri dengan tetap meningkatkan percaya diri terhadap kegiatan yang positif dan presatsi belajar tanpa merasa minder agar kelak menjadi orang yang tetap menjadi orang yang memiliki rasa percaya diri dan prestasi yang tinggi.

Penelitian selanjutnya dengan tema yang sama agar mengambil sampel yang berbeda agar lebih bervariatif dan inovatif. Selain itu juga bisa mengambil variabel yang lebih spesifik dari kepercayaan diri yaitu self-efficacy. Hal ini dikarenakan self-efficacy merupakan isu yang sedang trend pada penelitian social learning theory.

\section{UCAPAN TERIMAKASIH}

Melalui artikel jurnal penelitian ini, kami selaku penulis artikel ingin mengucapkan terima kasih kepada stake holder pejabat program studi di lingkungan Fakultas Tarbiyah dan Tadris IAIN Bengkulu. Khususnya kepada Bapak Dekan Dr. Zubaedi, M.Ag., M.Pd., Kaprodi Pendidikan Anak Usia Dini, Fatrica Syafri, M.Pd dan Kaprodi Tadris IPA Abdul Azis Bin Mustamin, M.Pd.I. . Selain itu juga kami mengucapkan terima kasih kepada para mahasiswa yang di lingkungan IAIN Bengkulu yang ikut membantu dari segi sarana dan prasarana penelitian, sehingga membantu kelancaran proses penelitian.

\section{DAFTAR PUSTAKA}

Ameliah, I. H., \& munawaroh, mumun. (2016). Pengaruh Keingintahuan Dan Rasa Percaya Diri Siswa Terhadap Hasil Belajar Matematika Kelas VII MTS Negeri I Kota Cirebon. Eduma: Mathematics Education Learning and Teaching, 5(1).

Ansarin, A. A., \& Khatibi, S. P. (2018). The Relationship Between Multiple Intelligences and Language Learning Strategies and Gender. English Language Teaching, 11(5), 84.

Anthony, R. (1992). Rahasia Membangun Kepercayaan Diri (terjemahan Rita Wiryadi). Jakarta: Binarupa Aksara.

Arikunto, S. (2010). Manajemen Penelitian. Jakarta: Rineka Cipta.

Arikunto, S. (2014). Metode Penelitian Kuantitatif, Kualitatif, dan Kombinasi (Mixed Methods). Bandung: Alfabeta.

Azman, A. R., Muhammad, S. S., Nurkhamimi, Z., \& Hasanah, A. K. (2018). An evaluation of Global Zakat Game (GZG) as edutainment board game in enhancing Zakat education in Malaysia. Educational Research and Reviews, 13(5), 166-172.

Bandura, A. (1997). Self-Efficacy. New York: Academic Press.

Bekleyen, N. (2011). Can I Teach English to Children? Turkish Preservice Teacher Candidates and Very Young Learners. Journal of Early Childhood Teacher Education, 32(3), 256-265.

Desi Putrianasari, D., \& Wasitohadi, W. (2015). Pengaruh Penerapan Pendekatan Contextual Teaching And Learning (CTL) Terhadap Hasil Belajar Matematika Ditinjau dari Motivasi Belajar Siswa Kelas 5 SD Negeri Cukil 01 Kecamatan Tengaran - Kabupaten Semarang. Scholaria: Jurnal Pendidikan Dan Kebudayaan, 5(1), 57.

Djamarah, S. B. (2008). Psikologi Belajar. Jakarta: Rineka Cipta.

Effendi, E., Mursilah, M., \& Mujiono, M. (2018). Korelasi Tingkat Perhatian Orang Tua dan Kemandirian Belajar dengan Prestasi Belajar Siswa. Titian Ilmu: Jurnal Ilmiah Multi Sciences, 10(1), 17-23.

Franke, G., \& Bogner, F. X. (2013). How does integrating alternative conceptions into lessons influence pupils' situational emotions and learning achievement? Journal of Biological Education, 47(1), $1-11$. 
Gael, L. (1994). Mendidik Anak agar Percaya Diri (Alih Bahasa: Ediati Kamil). Jakarta: Arcon.

Hakim, T. (2002). Belajar Secara Efektif. Jakarta: Puspa Swara.

Hamalik, O. (2001). Proses Belajar Mengajar. Jakarta: Bumi Aksara.

Hambly, K. (1992). Psikologi Populer: Bagaimana Meningkatkan Rasa Percaya Diri (terjemah oleh FX Budiyanto). Jakarta: Arcan.

Hutauruk, D. S., Maulina, I., \& Manik, Y. M. (2018). Hasil Belajar Siswa Dengan Strategi Pemberdayaan Berpikir Melalui Pertanyaan (PBMP) di SMA Negeri 5 Medan. Didaktika Biologi: Jurnal Penelitian Pendidikan Biologi, 2(1), 33-40.

Ibrahim, D. S., \& Suardiman, S. P. (2014). Pengaruh Penggunaan E-Learning Terhadap Motivasi dan Prestasi Belajar Matematika Siswa SD Negeri Tahunan Yogyakarta. Jurnal Prima Edukasia, 2(1), 66.

Ismiyati, I. (2015). Peningkatan Prestasi Dan Motivasi Belajar Ppkn Siswa Kelas VIII A SMP Negeri 2 Gedangsari - Gunungkidul Melalui Pembelajaran Group Investigation. Scholaria: Jurnal Pendidikan Dan Kebudayaan, 5(1), 39.

Jamil, M. M. (2019). Optimalisasi Model ARCS Dalam Pembelajaran Saintifik Untuk Meningkatkan Motivasi Belajar Peserta Didik Pada Peminatan Mata Pelajaran Geografi Di Kelas Matematika Ilmu Alam. IJIS Edu : Indonesian Journal of Integrated Science Education, 1(1), 7-24.

Juita, R. (2019). Meningkatkan Hasil Belajar IPA Melalui Metode Eksperimen Pada Siswa Kelas IV SDN 02 Kota Mukomuko. IJIS Edu : Indonesian Journal of Integrated Science Education, 1(1), 43-50.

Kusumah, R. G. T., \& Munandar, A. (2017). Analysis Of The Relationship Between Self Efficacy And Healthy Living Conciousness Toward Science Learning Outcome. EDUSAINS, 9(2), 132-138.

Liu, W., Zhang, H., Chen, X., \& Yu, S. (2018). Managing consensus and self-confidence in multiplicative preference relations in group decision making. Knowledge-Based Systems, 162, $62-73$.

Liu, X., Xu, Y., Montes, R., \& Herrera, F. (2019). Social network group decision making: Managing self-confidence-based consensus model with the dynamic importance degree of experts and trust-based feedback mechanism. Information Sciences, 505, 215-232.

Mawardi, M., Kristin, F., Anugraheni, I., \& Rahayu, T. S. (2019). Penerapan Pelatihan Partisipatif Pada Kegiatan Penulisan Dan Publikasi Karya Ilmiah Bagi Guru SD. Scholaria: Jurnal Pendidikan Dan Kebudayaan, 9(2), 132-137.

Nashar. (2004). Peranan Motivasi dan Kemampuan Awal dalam Kegiatan Pembelajaran. Jakarta: Delia Press.

Nath, S. R. (2012). The role of pre-school education on learning achievement at primary level in Bangladesh. International Journal of Early Years Education, 20(1), 4-14.

Nawawi, H. (1998). Metode Penelitian Bidang Sosial. Yogyakarta: Gadjah Mada University Press.

Novena, V. V., \& Kriswandani, K. (2018). Pengaruh Model Pembelajaran Probing Prompting Terhadap Hasil Belajar Ditinjau Dari Self-Efficacy. Scholaria: Jurnal Pendidikan Dan Kebudayaan, 8(2), 189-196.

Riduwan. (2015). Dasar-Dasar Statiska. Bandung: Alfabeta.

Sardiman, A. M. (2004). Interaksi \& Motivasi Belajar Mengajar. Jakarta: Rajagrafindo.

Sari, I. K., \& Yunianta, T. N. H. (2017). Efforts To Improve Math Learning Result Of Fourth Grade Students Through Contextual Model Teaching And Learning With Cuisenaire Rods Media. Scholaria : Jurnal Pendidikan Dan Kebudayaan, 7(2), 143. 
Pengaruh Rasa Percaya Diri Terhadap Motivasi Berprestasi Siswa pada Mata Pelajaran IPA

(Asiyah, Ahmad Walid, Raden Gamal Tamrin Kusumah)

Sharour, L. A. (2019). Improving oncology nurses' knowledge, self-confidence, and self-efficacy in nutritional assessment and counseling for patients with cancer: A quasi-experimental design. Nutrition, 62, 131-134.

Shen, B., McCaughtry, N., Martin, J., \& Fahlman, M. (2009). Effects of Teacher Autonomy Support and Students' Autonomous Motivation on Learning in Physical Education. Research Quarterly for Exercise and Sport, 80(1), 44-53.

Strayhorn, T. L. (2008). How College Students' Engagement Affects Personal and Social Learning Outcomes. Journal of College and Character, 10(2).

Suarni, E. (2019). Upaya Meningkatkan Hasil Belajar Matematika Siswa Kelas III Dengan Menggunakan Pendekatan Inkuiri Terbimbing Di SDN 05 Kota Mukomuko. IJIS Edu: Indonesian Journal of Integrated Science Education, 1(1), 63-70.

Sudijono, A. (2010). Pengantar Statistik Pendidikan (22nd ed.). Rajawali Pers: Rajawali Press.

Sulistyorini, S. (2007). Pembelajaran IPA Sekolah Dasar. Yogyakarta: Wacana.

Surya, H. (2007). Percaya Diri Itu Penting. Jakarta: Elex Media Komputindo.

Tagg, B., \& Wang, S. (2016). Globalisation, commercialisation, and learning to play at KidZania Kuala Lumpur. International Journal of Play, 5(2), 141-158.

Tu’u, T. (2004). Peran Disiplin Pada Perilaku Dan Prestasi Siswa. Jakarta: Grasindo.

Walid, A., Putra, E. P., \& Asiyah. (2019). Pembelajaran Biologi Menggunakan Problem Solving Disertai Diagram Tree Untuk Memberdayakan Kemampuan Berpikir Logis Dan Kemampuan Menafsirkan Siswa. IJIS Edu: Indonesian Journal of Integrated Science Education, 1(1), 1-6.

Wijaya, C. (1992). Kemampuan Dasar Guru Dalam Proses Belajar Mengajar. Bandung: Remaja Rosdakarya.

Wijekoon, C. N., Amaratunge, H., De Silva, Y., Senanayake, S., Jayawardane, P., \& Senarath, U. (2017). Emotional intelligence and academic performance of medical undergraduates: A crosssectional study in a selected university in Sri Lanka. BMC Medical Education, 17(1), 1-11.

Yusrizal, Y., Suliyanah, S., \& Basri, T. H. (2017). Analysis of Knowledge, Understanding and Skills of Physics Teachers of State Senior High Schools in Developing and Analyzing Test Items. Jurnal Pendidikan IPA Indonesia, 6(2), 335-340. 